\title{
Predicting children's academic achievement after the transition to first grade: A two-year longitudinal study
}

\author{
Goele Bossaert ${ }^{\mathrm{a}, *}$, Sarah Doumen ${ }^{\mathrm{b}}$, Evelien Buyse ${ }^{\mathrm{a}}$, Karine Verschueren ${ }^{\mathrm{b}}$ \\ a Department of Educational Sciences, Katholieke Universiteit Leuvenn, Belgium \\ b Department of Psychology, Katholieke Universiteit Leuven, Belgium
}

\section{A R T I C L E I N F O}

Article history:

Received 3 June 2008

Received in revised form 14 December 2010

Accepted 14 December 2010

Available online 26 January 2011

\section{Keywords:}

School transitions

Kindergarten

First grade

Academic achievement

\begin{abstract}
A B S T R A C T
The transition from kindergarten to first grade has been described as a critical period for children's academic development. Furthermore, research indicates that peer status is connected with academic adjustment, yet the underlying processes remain unclear. By means of a two-year longitudinal study during kindergarten and first grade $(N=153)$, we aimed to shed light on the antecedents of achievement at the end of first grade. Based on the parallel processes mediation model (Buhs, 2005), a comprehensive predictive model was constructed and tested. Results showed that (a) the parallel processes mediation model is partially valid during the transition from kindergarten to first grade; and (b) there is more support for an effect of academic self-concept on achievement than vice versa. This comprehensive model increases our insight in the factors that enhance children's academic development during the transition to first grade.
\end{abstract}

(c) 2010 Elsevier Inc. All rights reserved.

\section{Introduction}

In most educational systems, formal education starts around the age of six, when children move to first grade. The transition to first grade has been described as a critical period for children's development in general and their academic development in particular (Entwisle \& Alexander, 1998). Not only does the child himself or herself undergo profound developmental changes (e.g., its cognitive skills), the child's learning environment changes as well. In first grade, children are exposed to more teacher-directed and seatwork activities, in a much more academically oriented environment (La Paro, Rimm-Kaufman, \& Pianta, 2006; Sink, Edwards, \& Weir, 2007). First grade academic performance is especially critical because of the cumulative nature of the curriculum: It is hard for children to achieve at a high level in later grades, without achieving at a high level in earlier grades. Therefore, understanding the factors that shape early achievement is important and may have implications for early mobilization of educational resources (Downer \& Pianta, 2006; Ladd, Birch, \& Buhs, 1999).

Recent research has focused on the effects of peer relationships on academic achievement and school adjustment processes in general (e.g., Ladd, Herald, \& Kochel, 2006; Rubin, Bukowski, \& Laursen, 2009). Based on these and former studies, it has become obvious that peer acceptance

\footnotetext{
* Corresponding author. Parenting and Special Education Research Group, Andreas Vesaliusstraat 2, Box 3765, B-3000 Leuven, Belgium. Tel.: +32 16 325940; fax: +32 16 325933.

E-mail addresses: goele.bossaert@ped.kuleuven.be (G. Bossaert), sarah.doumen@psy.kuleuven.be (S. Doumen), evelien.buyse@ped.kuleuven.be (E. Buyse), karine.verschueren@psy.kuleuven.be (K. Verschueren).
}

accounts for unique variance in children's school adjustment (e.g., Ladd, Kochenderfer, \& Coleman, 1997; Lubbers, Van der Werf, Snijders, Creemers, \& Kuypers, 2006). However, questions still remain about the intervening processes that may explain the link between peer relationship variables and academic outcomes (Wentzel, 2003). Contemporary research focuses on developing peer-oriented models of relationship effects on adjustment patterns (e.g., Buhs, 2005; Buhs, Ladd, \& Herald, 2006; Flook, Repetti, \& Ullman, 2005; Ladd et al., 1999; Lubbers et al., 2006; Wentzel, 2003; Wentzel \& Caldwell, 1997). However, to our knowledge, no comprehensive, longitudinal model including peer-relationship variables has been tested regarding students' academic adjustment in first grade. The few studies that have examined effects of peer acceptance on first grade achievement (e.g., O'Neil, Welsh, Parke, Wang, \& Strand, 1997) did not include possible intervening mechanisms. Moreover, they failed to examine effects of peer acceptance alongside of other relevant factors, such as entry factors and kindergarten achievement.

Associations between peer acceptance, self-concept, classroom engagement, and achievement: A process-oriented model

Recently, Buhs (2005) developed a process-oriented model to explain the effect of peer relationships on academic achievement, called the 'parallel processes mediation model'. This model is based on motivational frameworks, in particular the self-system model of motivational development (Connell, 1990; Connell \& Wellborn, 1991; Skinner, Furrer, Marchand, \& Kindermann, 2008), as well as on developmental research regarding the role of peer relationships for children's development (Coie, 1990; Harter, 1998). Central explaining processes in Buhs's model, linking peer relationships to academic 
achievement, are academic self-concept and classroom engagement. Buhs's model describes academic self-concept and classroom engagement as two mediators, acting both linear or sequentially (from academic self-concept to classroom engagement) and parallel, in explaining the link between peer acceptance and academic achievement.

\section{Academic self-concept and classroom engagement as parallel mediating processes}

To explain the mediating role of classroom engagement in the link between the peer relationship context and academic achievement, Buhs (2005) refers to former longitudinal studies on the consequences of early peer rejection, showing that one aspect of children's responses following peer rejection is disengagement in school activities (e.g., Buhs \& Ladd, 2001). Several explanations have been provided for the negative effect of peer rejection on engagement (Buhs \& Ladd, 2001; Wentzel, 2004). First, rejected children, who tend to be treated more negatively by the peer group, may withdraw from or avoid classroom activities that include abusive companions; second, rejected children may fear that the requested help will not be freely offered; and third, rejected children might believe that they will not value what their peer group values or behave as the group behaves. Positively phrased, peer provisions have the potential to influence students' internalized reasons for goal pursuit. They have the potential to make engagement in a task fun, important or interesting (Wentzel, 2004).

In its turn, classroom engagement is considered a key antecedent of academic achievement (Fredricks, Blumenfeld, \& Paris, 2004). Buhs (2005) focuses on the behavioral dimension of classroom engagement and conceptualizes it as cooperative classroom participation or "children's adoption to the 'student role' and compliance with classroom social rules and expectations" (Ladd, Herald-Brown, \& Reiser, 2008, p. 1002) and independent classroom participation or “children's propensity to take initiative" (Ladd et al., 2008, p. 1002). In previous longitudinal investigations, classroom participation turned out to be a significant predictor of later achievement (e.g., Ladd et al., 1999). A higher level of classroom participation represents an adaptive response to the school culture. This way, children will be more likely to have experiences that foster learning and skill development (Finn, 1993; Ladd et al., 1999). This makes classroom engagement a key intervening construct linking peer acceptance to later achievement.

To explain the mediating role of academic self-concept in the link between peer relationships and academic achievement, Buhs (2005) draws on Harter's (1998) ideas about the significance of peer approval or disapproval for the development of individual differences in children's self-perceptions. Empirical studies have confirmed that peer relationships are linked to several aspects of the self-concept, including academic self-concept (e.g., Boivin \& Hymel, 1997; Juvonen, Nishina, \& Graham, 2000; Tarquin \& Cook-Cottone, 2008). This link might become more important in contemporary classrooms because peer-mediated activities (e.g., cooperative learning groups) are increasingly used to promote classroom learning and achievement (e.g., Jabionsky, 2009). In its turn, academic self-concept (or "students self-perceptions of their ability, enjoyment of, and interest in school subjects in general"; Marsh, Craven, \& Debus, 1998, p. 1051) is believed to be an important aspect of the self-concept to enhance academic achievement (Harter, 1998). The contention that positive self-beliefs, and a positive academic self-concept in particular, have a favorable effect on academic achievement, even after controlling for prior levels of achievement, is central to the 'self-enhancement' hypothesis (Byrne, 1984). Increased student effort, persistence in the face of difficulties, enhanced intrinsic motivation, academic choice and coursework selection have been mentioned as mechanisms explaining this effect (Marsh, Byrne, \& Yeung, 1999). Especially during school transition periods, positive self-beliefs have been found to contribute to a successful transition (Simmons \& Blyth, 1987).

Academic self-concept and classroom engagement as linear mediating processes

According to Buhs (2005), academic self-concept and classroom engagement do not only operate as parallel mediating processes, each having direct links with (prior) peer relationships and (later) academic achievement. Academic self-concept is also assumed to indirectly affect academic achievement, through its effect on classroom engagement. This assumption of sequentially related processes, which mediate the link between peer relationships and academic achievement, stems from the self-system model of motivational development (Connell, 1990; Connell \& Wellborn, 1991), also referred to as the 'context-self-action-outcome' model. The model affirms that interpersonal contexts shape individuals' beliefs about themselves within a particular setting, such as schools. These beliefs determine how engaged or disaffected they will be in that particular setting. Academic and behavioral adjustment form the outcomes of engagement in the educational setting. Building on this model and applying it to peer relationships, Buhs (2005) hypothesized that similar sequential linkages exist between relational features of context (peer acceptance versus rejection), aspects of self (academic self-concept), subsequent action patterns (classroom engagement), and achievement outcomes (changes in achievement).

To summarize, according to Buhs's model academic self-concept and classroom engagement are sequentially interconnected and operate as parallel mediating processes in the connection between peer acceptance and achievement outcomes.

\section{Present study}

Expanding the parallel processes mediation model explained above, we built a comprehensive model, which focuses on the transition period between kindergarten and first grade and predicts achievement level at the end of first grade from variables measured in kindergarten and during first grade, taking into account relevant entry factors (Fig. 1). The model summarizes our research goals.

Until now, the parallel processes mediation model has been tested and confirmed in a short-term longitudinal study across fifth grade (Buhs, 2005). So far, the model has only been replicated in adapted forms, omitting academic self-concept (Buhs et al., 2006; Hoglund, 2007). The first goal of the current study was to test whether the parallel processes mediation model as originally proposed by Buhs also holds in early schooling phases. Based on former longitudinal studies (e.g., Buhs \& Ladd, 2001), we expected to find a mediating role of classroom engagement in the link between the peer relationship context and academic achievement. It is less clear whether the mediating role of academic self-concept and the sequential interconnection of academic self-concept and classroom engagement will also hold for young children (see further).

The second goal pertained to the duration of the process. Until now, Buhs's model has only been tested over short periods of time, that is, from Fall to Spring in the same school year. In our study, we wanted to test whether the model still holds over a longer period of time. More specifically, we aimed to test the validity of the model to predict achievement at the end of first grade from variables before the transition to formal education, that is, assessed during kindergarten.

Third, the parallel processes mediation model (Buhs, 2005), tested among fifth graders, proposed academic self-concept to be an antecedent of subsequent achievement (i.e., 'self-enhancement model'). Contradictorily, earlier studies among elementary school samples found support for a 'skill-development model', in which academic self-concept is a consequence of prior achievement (e.g., Skaalvik \& Hagtvet, 1990). Furthermore, in a recent study with 


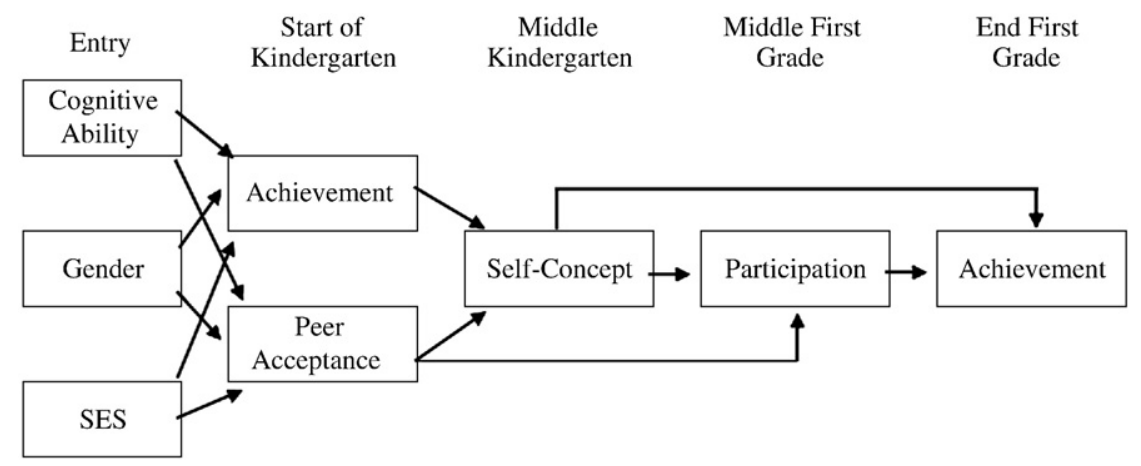

Fig. 1. The hypothesized predictive model of achievement at the end of first grade. SES = Socioeconomic status.

second, third, and fourth graders, support for reciprocal effects between academic self-concept and achievement was found (Guay, Marsh, \& Boivin, 2003). We found no studies, however, concerning the link and the underlying processes between academic self-concept and achievement for kindergartners and first graders. Results concerning the link, and more importantly, the direction of effects between academic self-concept and academic achievement among young children are lacking. Furthermore, because questions remain about the causal predominance of both variables among young children, in the current study, both directions of effects (from kindergarten achievement to academic self-concept and from academic selfconcept to first grade achievement) were explicitly modeled. Consequently, we included prior achievement at the beginning of kindergarten in the model, to test these hypotheses. In this manner, we aimed to test if and how self-enhancement and skill-development processes work together in the prediction of first grade achievement.

Fourth, our aim was to test effects of peer acceptance and achievement in kindergarten on first grade achievement, taking into account relevant entry factors. Entry factors are child and/or environmental attributes that operate prior to children's school entrance, but impact their adaptive success after they enter kindergarten (e.g., Ladd et al., 1999). Important entry factors, also included in the current study, are cognitive ability or intelligence, gender, and socioeconomic status (SES) (Ladd et al., 1999; Teddlie \& Reynolds, 2000). Although strong positive correlations exist between intelligence and performance on standardized achievement tests (Naglieri \& Bornstein, 2003; Worland, Weeks, Janes, \& Strock, 1984), recent research supports the distinctiveness of both concepts and points to the causal precedence of psychometric IQ to achievement (Lubinski \& Dawis, 1992; Watkins, Lei, \& Canivez, 2006). Therefore, we decided to include both cognitive ability and kindergarten achievement in the model we tested.

These considerations resulted in a comprehensive, multivariate process model (Fig. 1) including three entry factors (cognitive ability, gender, and SES), two variables (i.e., achievement and peer acceptance) in the beginning of kindergarten, one variable in the middle of kindergarten (i.e., academic self-concept), and one variable in the middle of first grade (i.e., classroom participation). The sequencing of these central constructs and their assessments was informed by the theoretical models explained above. The integration of all these antecedents allowed us to acquire a more precise view on how these variables relate with each other over time and affect achievement at the end of first grade.

\section{Method}

\section{Participants}

The research was conducted in Flanders, the Dutch-speaking part of Belgium. In Belgium, most children pass through at least three preschool grades before they enter compulsory primary education around the age of six. In the final preschool year (kindergarten), several skills are taught, ranging from language acquisition and motor development to social skills. Primary education continues to build on this process (Ministry of the Flemish Community, Educational Information and Documentation Division, 2005). Nonetheless, formal education only starts when children move to first grade (Verachtert, 2008), and, as in other countries, kindergarten education is generally more similar to preschool education than to education in first grade (La Paro, Pianta, \& Cox, 2000).

Sample selection proceeded before the onset of kindergarten. Thirty schools agreed to participate after telephoning them to explain the study. Because data were collected from parents, children, classmates, and teachers, in kindergarten and in first grade, all of these groups were asked either written informed consent or oral consent. Parental written consent was obtained from all participating children. Classrooms with at least six children with parental permission to engage in the study were selected. When children changed schools between giving permission and the actual start of the study, the new school was contacted and asked for participation as well. To collect data from classmates regarding the participants' level of peer acceptance, a passive consent procedure was used. We preferred to work with passive consent in order to maximize the number of children involved in the peer nomination procedure in each classroom. A letter, explaining the goal of the study, was sent to the parents of all the children in the selected classrooms. If parents did not want their child to participate or to be photographed, they were asked to contact the researchers via the specified phone numbers or email address. This way, we obtained parental consent for participation in the larger longitudinal study for 239 children. Due to the emigration of two children, 237 children remained at the start of kindergarten.

Because this study was part of a larger longitudinal study, including several questionnaires and observations, we decided to randomly select three boys and three girls, whenever parental permission was received for more than six children. Selection of students was necessary due to time restrictions and to prevent overloading the teachers with extra work. By selecting six children per classroom, we obtained data from a wide range of classes in the study. Consequently, for a core sample of 169 children within this larger longitudinal study, all classroom measurements, i.e., including the self-concept questionnaires, were administered. For the core sample, 153 of the 169 children were still participating in the longitudinal study in first grade. Dropout $(n=16)$ was mainly due to children changing schools and/or families moving. These 153 children formed the sample for the current study.

We checked for possible differences, by means of $t$-tests for independent samples, between the core sample $(N=153)$ and the non-selected children from the larger longitudinal sample $(N=84$, i.e., 237-153; gender $=t(235)=-0.07, p>.05$; cognitive ability $=$ $t(227)=0.77, p>.05$; socioeconomic status $=t(192)=3.34, p<.01$; language test at beginning of kindergarten $=t(233)=0.19, p>.05$; 
arithmetic concept test at beginning of kindergarten $=t(231)=1.07$, $p>.05$; peer acceptance $=t(228)=0.62, p>.05$; cooperative participation in first grade $=t(202)=0.54, p>.05$; independent participation in first grade $=t(202)=-0.03, p>.05$; spelling at the end of first grade $=t(196)=-1.93, p>.05$; reading chart $1=t(195)=$ $-0.72, p>.05$; reading chart $2=t(195)=-0.38, p>.05$; reading chart $3=t(195)=-0.74, p>.05$; and mathematics at the end of first grade $=t(193)=0.92, p>.05)$. Differences were tested for all variables except academic self-concept, which was not assessed in the larger sample because of practical considerations (see earlier). Only one $t$-test yielded a significant difference for socioeconomic status. The effect size was rather small $(0.23)$. We can conclude that the socioeconomic status of the students in the core sample $(N=153)$ was slightly higher compared to the socioeconomic status of non-selected students in the larger longitudinal sample $(N=84)$.

The participating children of the core sample ( $48 \%$ boys) had a mean age of five years and two months at kindergarten entry. For the majority of the children (88\%), both parents had the Belgian nationality. The educational level of each of the parents was recorded. Seventy-one percent of the mothers completed higher education (i.e., college or university graduate, equaling more than twelve years of schooling in total), $17 \%$ finished some years of high school (six to twelve years of schooling), and one mother finished primary school (six years of schooling). Fifty-six percent of the fathers obtained a higher education degree, $25.5 \%$ of them finished (some years of) high school, and one father completed primary school.

In kindergarten, the 153 children were divided over 36 classes in 26 schools. Schools were situated in rural to moderately urban areas (populations ranged from about 9000 to 90 000; Algemene Directie Statistiek en Economische Informatie, 2004). Due to children changing classrooms or schools between selection for participation and the start of the study, the number of participating children per classroom finally ranged between 1 and 9 in kindergarten classrooms $(M d n=4.5)$. Kindergarten classroom size ranged between 8 and 39 children $(M=20.83 ; S D=5.45)$.

After the transition to first grade, 42 classes and their teachers participated. The number of participating children in first grade per classroom ranged between 1 and $9(M d n=4)$. For 39 out of 42 classes, classroom sizes ranged from 11 to $24(M=18.26$; $S D=3.19)$. Teachers in these classes were on average 39.59 years old $(S D=9.93$ years) and had on average 16.73 years of teaching experience $(S D=$ 9.24 years). For the remaining three classes no information regarding classroom size and teacher experience was available. Out of the 42 teachers, 8 were male.

\section{Procedure}

In kindergarten, data were gathered in three waves. Before or at the very beginning of kindergarten (within the first month of the school year), data on the entry factors were collected (i.e., cognitive ability, gender, and SES). A demographic questionnaire, including questions about the child's gender, educational level of both parents, and ethnicity of the child, was delivered personally and filled out by the parents. Researchers administered a cognitive ability test in small groups. During the second wave (October-December 2004), children's achievement at the beginning of kindergarten was measured in small groups in a separate classroom by a researcher by means of a standardized school readiness test. Group sizes ranged from 1 to 14 ( $M d n=9$ for language; $M d n=8$ for arithmetic concepts). Tests for arithmetic concepts and language were administered on two different days.

Furthermore, data concerning peer acceptance were collected from the participants' classmates. Individual sociometric ratings were used to probe peer acceptance. In the third period of data-collection (January-March 2005), data on children's academic self-concept were collected from all participants individually. Participants responded orally to the questions asked by the researcher. To ensure adequate understanding, at the start of the session, children were trained in using the response format and were urged to ask questions whenever something was not clear.

During first grade, there were two waves of data collection. In the first wave (January-March 2006), children's classroom participation was assessed by means of a teacher-rated questionnaire. The second wave took place at the end of the school year (April-June 2006), when children's achievement level was again measured by means of standardized tests. The spelling and mathematics test were administered collectively from all students, in their respective classrooms. The reading test was administered individually in a separate room. A research assistant administered all achievement tests.

\section{Measures}

\section{Cognitive ability}

To probe children's cognitive ability, the Coloured Progressive Matrices test (CPM; Raven, 1956; Raven, Court, \& Raven, 1977) was used. The CPM is a non-verbal intelligence test, created for children between 5 and 11 years old. The CPM has sufficient reliability, construct, and criterion validity (e.g., Evers, van Vliet-Mulder, \& Groot, 2000). The CPM consists of 36 items, spread over 3 subsets of 12 items each, leading to a maximum score of 36 . Internal consistency (Cronbach's alpha), based on the subset scores was .75 in the present study. For children under the age of eight, the CPM is typically administered individually, because the response format is too difficult (Raven et al., 1977). In this study, the CPM was administered in a separate classroom by one researcher in small groups of 1 to 13 children $(M d n=8)$. To be able to administer this test in small groups, the original response sheet was simplified. Instead of a single response sheet, a response booklet was created. Each response sheet within the booklet was divided into four sections, each representing a particular question. Each section was marked with a stamp that corresponded with the stamp next to the question in the test booklet. This visual mark made it easier for children to follow. Each section on the response sheet contained six figures or response possibilities. Within each section, the child had to mark one of the six figures that, in his/her view, represented the right answer. The researcher walked through the classroom to identify and solve possible problems or questions of the children.

\section{Socioeconomic status}

In the present study, SES was tapped by means of parents' education level, that is, their highest obtained educational degree. When relying on a single indicator to evaluate a family's SES, parents' educational level seems to be the most reliable (Alexander, Entwisle, Blyth, \& McAdoo, 1988). Parents' educational level was measured on a six-point scale, ranging from low (primary school) to high (obtained a university degree). In order to obtain a single variable, the highest educational level of both parents was retained. Thirty-eight percent of the parents had a similar educational degree. In $43 \%$ there was a difference in degree level between partners (21\% favoring mothers, $22 \%$ favoring fathers). For 11 children only the mother's degree was known and for 2 children only the father's degree was filled out.

\section{Kindergarten achievement}

To assess academic achievement at the beginning of kindergarten, standardized school readiness tests used in a large-scale longitudinal study of school trajectories in elementary schools in Flanders were administered. The large-scale study comprised 3861 children from 122 schools, representative in Flanders in terms of school size, educational network, and geographical location (Study 'Schoolloopbanen in het BasisOnderwijs', SiBO; Maes, Ghesquière, Onghena, \& Van Damme, 2002). The tests consisted of both a language test for kindergartners (Verachtert, 2003) and an arithmetic concept test (Dudal, 1993; 
Verachtert, 2003). The language test is a Flemish version of a widely used and validated Dutch language test (Van Kuyk, 1996; see Evers et al., 2002 for information on validity). The test consists of 40 items, leading to a maximum score of 40 . Internal consistency (Cronbach's alpha) of the item scores was .86 in the large-scale SiBO study and .81 in the present study. The arithmetic concept test also consists of 40 items (maximum score of 40) and was especially designed for use in the SiBO study. Evidence supporting its reliability and validity has been gathered (Verachtert, 2008). Internal consistency of the item scores was .93 in the SiBO study, and 0.92 in the present study. Furthermore, in the current study, scores on both tests entailed almost the entire theoretical range. The correlation between scores for both tests was high $(r=.64, p<.001$; Cohen, 1988). Therefore, scores for both tests were standardized and summed to obtain an overall achievement score.

\section{Peer acceptance}

To assess peer acceptance, the sociometric procedure of Asher, Singleton, Tinsley, and Hymel (1979) was used. Peer ratings were used, meaning that scores could be calculated for all children, including those that may not have received any nominations if positive/negative nomination procedures had been used (Bukowski \& Hoza, 1989). Photographs were taken of all children in the classroom who received parental permission for participation in the sociometric procedure. After identifying all his or her classmates from photographs, a child was asked to what extent he/she liked to play with the child in the picture pointed at, by putting the photograph in a green box with a happy face (for 'like to play with' answers), a red box with a sad face (for 'do not like to play with' answers), or a yellow box with a neutral face (for 'kind of like to play with' answers). These answers were scored as 3,1 , or 2 respectively. The index of peer acceptance calculated represented the mean score the child received from his/her classmates, standardized per classroom. Higher scores reflected more peer acceptance. This sociometric procedure has produced satisfactory test-retest stability across different preschool settings (Asher et al., 1979; Ladd \& Coleman, 1993; Ladd et al., 1999).

\section{Academic self-concept}

Self-concept was assessed by means of the subscale General School of the Self Description Questionnaire (SDQ-I; Marsh, 1988). In the General School scale, the child's evaluation of his/her ability, enjoyment, and interest in school subjects is measured (six items; e.g., 'I am good at all school subjects'). In the original version, the subscale contains eight items. After refining the Dutch version in a pilot study, two out of eight items which appeared to be difficult to understand for most children, were dropped. Marsh, Craven, and Debus (1991) used the original instrument in a study with kindergartners, first, and second graders, with satisfying results concerning internal consistency. The alpha coefficient for kindergartners equaled .72 for the General School subscale. In our study, the internal consistency of the translated and adapted subscale General School was a little higher, with an alpha coefficient of .79.

\section{Classroom participation}

Classroom participation was assessed by means of the Teacher Rating Scale of School Adjustment (TRSSA; Birch \& Ladd, 1997; Ladd, 1992). This instrument has four subscales of which two refer to classroom participation, as described in the introduction. The subscale Cooperative Participation consists of eight items (e.g., 'Listens carefully to teacher's instructions and directions'). The subscale Independent Participation contains nine items (e.g., 'Works independently'). All items are rated on a scale from 1 (does not apply) to 3 (certainly applies). Subscale scores are obtained by averaging item scores of the specific subscale. The internal consistency, as reported by Birch and Ladd (1997) for Cooperative Participation equaled .92 and for Independent Participation equaled .91. In the current study, internal consistency for Cooperative and Independent Participation was similar, with $\alpha=.85$ and $\alpha=.90$ respectively. Because the correlation between both subscales was $r=.63(p<.001)$, and in agreement with Ladd et al. (1999), both scores were summed to yield a general classroom participation score.

\section{First grade achievement}

To assess achievement at the end of first grade, language tests (i.e., a spelling and a reading test) and a mathematics test from the largescale longitudinal study mentioned before (SiBO; Maes et al., 2002) were used. Spelling was assessed using a Flemish version of a widely used and validated Dutch spelling test (B-version; Moelands \& Rymenans, 2003a; Rymenans, 2000; see Evers et al., 2002 for information on its validity). The test consists of 39 exercises, yielding a maximum score of 39. The internal consistency of the item scores in the SiBO study was high $(\alpha=.92$; Verachtert, Ghesquière, Hendrikx, Maes, \& Van Damme, 2005). In the current study, internal consistency was .88. The reading test (Moelands, Kamphuis, \& Rymenans, 2003; Moelands \& Rymenans, 2003b), a Flemish version of a well-validated Dutch test (see Evers et al., 2002, for evidence concerning validity), contains three reading charts with words of increasing difficulty. For each chart, the child was asked to read as many words as accurately as he/she could for $1 \mathrm{~min}$. The number of correctly read words was recorded. Pearson correlation coefficients between the scores for the three reading charts were high ( $r=.90-.95$; Verachtert et al., 2005). In our study, correlation coefficients between the three reading charts were similar $(r=.89-.94, p<.001)$. To obtain a general language score, we averaged the standardized score for spelling and the standardized mean score for the reading charts. The correlation between the standardized scores for spelling and the mean score for the reading charts was .42 $(p<.001)$.

The mathematics test (Dudal, 2006) consists of 40 items, comprising number sense, arithmetic word problems, estimation, number decomposition, and number series. Internal consistency of the item scores proved to be high in the original SiBO study ( $\alpha=.92$; Verachtert et al., 2005) as well as in our study ( $\alpha=.92$; see Verachtert, 2008 for evidence supporting its validity).

To obtain an overall achievement score, the standardized mathematics score and the standardized language score (as described above) were summed. The correlation between scores for both measures was .51 $(p<.001)$.

\section{Results}

In a first step, bivariate correlations between all variables were computed. To test the direct and indirect effects as described in our hypothesized model (Fig. 1), we used path analysis in a second step.

To test whether multilevel techniques were required, design effects were evaluated (Muthén \& Satorra, 1995). In this sample, design effects for all variables were below the critical value of two (i.e., below 1.48). Therefore, single-level structural equation modeling was used. Furthermore, we needed to deal with missing values in our data. In a first step, we checked for possible differences between dropouts and completers within the core sample $(N=153)$. When comparing participants of whom all data were obtained and participants with at least one missing variable in the core sample, using a set of $t$-tests for independent samples, one out of eight $t$-tests was significant (i.e., achievement at the end of first grade). The effect size, however, was small (i.e., 0.18). Furthermore, because the missing data percentage was too high (7\%) and missing values were spread out over different variables, listwise or pairwise deletion would probably bias the results or generate an unacceptable loss of power (Peters \& Enders, 2002). Therefore, we preferred to estimate the missing values by means of maximum-likelihood estimation. Maximum-likelihood estimation produces good parameter estimates when data are strongly nonnormal, but may give underestimated standard errors and inflated chi-square leading to too frequent rejections of the null hypothesis. To 
protect against the effects of non-normality in our data, robust standard error computations, such as the MLR estimator and the Yuan Bentler chi square, were used (Muthén \& Asparouhov, 2002; Yuan \& Bentler, 2000). All analyses were carried out in Mplus, offering these options (Muthén \& Muthén, 1998-2001).

Path analyses were conducted in three steps. In the first step, the parallel processes mediation model (Buhs, 2005) was fitted. In a second step, achievement in kindergarten was added to test the validity of the skill-development hypothesis versus the self-enhancement hypothesis. In a third step, the effects of the entry factors on both achievement and peer acceptance in kindergarten were added and tested. Whenever necessary, specification searches were conducted in each step, before progressing to the next (MacCallum, 1986). Paths were added sequentially to improve fit and then deleted sequentially to enhance parsimony (Saris \& Stronkhorst, 1984; Ladd et al., 1999). As recommended in methodological literature (Kline, 2005; Suyapa, Silvia, \& MacCallum, 1988), alterations in paths were guided by both conceptual (i.e., theoretical relevance, plausibility) and empirical considerations (e.g., modification indices, indicators of fit). To assess model fit, the Yuan Bentler chi-square, the Steiger-Lind Root Mean Square Error of Approximation (RMSEA), the Standardized Root Mean Square Residual (SRMR) and the Comparative Fit Index (CFI) were inspected. The fit of the model was considered adequate if the chi square statistic was as small as possible, RMSEA was less than 0.06, SRMR was less than 0.08 and CFI exceeded 0.95 (Kline, 2005). Additionally, the Sobel (1982) test was used to test the significance of indirect effects.

\section{Preliminary analyses}

In Table 1, the descriptive statistics of the variables are displayed. Of importance is the range of the variables and especially the percentile scores of the achievement tests. Furthermore, we compared the mean scores and standard deviations of our sample with the mean scores and standard deviations of the same tests used in the large-scale longitudinal SiBO study (Verachtert, 2003; Verachtert et al., 2005).

In kindergarten, the scores of the language and arithmetic concept tests covered almost the entire range, with percentiles for the language scores ranging between 3 and 99; and for the arithmetic concept tests between 0 and 100 . However, the mean scores of the language and arithmetic tests of the children in the current sample significantly surpassed the mean scores of the children included in the
SiBO study (language: $t(151)=4.88, p<.001$; arithmetic concepts: $t(149)=7.91, p<.001)$.

In first grade, reading, spelling and mathematics were assessed. For the reading charts, typically percentile scores are not used. Instead, children are assigned to skill zones. Based on these data, we could conclude that almost the entire theoretical range of achievement levels was included in the study. No significant differences in the amount of correctly read words emerged between our sample and the SiBO sample (reading chart $1=t(140)=-0.08, p>.05$; reading chart $2=$ $t(140)=-0.52, p>.05$; reading chart $3=t(140)=-1.09, p>.05)$. For the spelling test, the percentiles ranged between 27 and 100. However, the mean scores of the spelling test in our sample did not differ from the mean scores in the SiBO sample $(t(140)=1.68, p>.05)$. For the mathematic tests, percentiles ranged from 1 to 99 , and no differences in mean scores between our sample and the SiBO sample were found $(t(141)=-0.89, p>.05)$.

\section{Bivariate relations among all variables}

As shown in Table 2, correlations between entry factors ranged from -.08 to .26. There was a positive correlation between scores for cognitive ability and SES. Furthermore, both were positively related with achievement scores at the beginning of kindergarten and at the end of first grade, and positively with classroom participation in first grade. Gender was positively related to peer acceptance in kindergarten and classroom participation in first grade, both in favor of girls.

There was a positive correlation between achievement and peer acceptance at the start of kindergarten. When we look at the correlations between the kindergarten variables and the variables measured in first grade, achievement at the beginning of kindergarten was related positively to cooperation and self-direction in class, and to achievement the following year. Furthermore, peer acceptance and academic self-concept in kindergarten were positively related to classroom participation in first grade. Finally, there was a significantly positive correlation between classroom participation in the middle of first grade and academic results at the end of that year.

\section{Predicting academic achievement: Path analysis}

In a first step the parallel processes mediation model of Buhs (2005) was tested. This model proved to have a good fit: $\chi^{2}(1)=0.01, p>.05$, RMSEA $=0.00$, SRMR $=0.00, C F I=1.00, R^{2}=0.22$. However, two paths

Table 1

Descriptive statistics for the variables in the study.

\begin{tabular}{|c|c|c|c|c|c|c|c|}
\hline Variables & $N$ & $M$ & $M_{\text {Sibo }}$ & $S D$ & $S D_{\text {Sibo }}$ & Range & Theoretical range/Skill zone \\
\hline \multicolumn{8}{|l|}{ Cognitive ability } \\
\hline CPM & 147 & 17.59 & & 5.30 & & $6.00-32.00$ & $0.00-36.00$ \\
\hline \multicolumn{8}{|c|}{ Kindergarten achievement } \\
\hline Language & 152 & 25.51 & 23.03 & 6.28 & 7.58 & $8.00-37.00$ & $0-40$ \\
\hline Arithmetic concepts & 150 & 31.29 & 26.34 & 7.67 & 9.36 & $4.00-40.00$ & $0-40$ \\
\hline \multicolumn{8}{|l|}{ Peer acceptance } \\
\hline Raw ratings & 147 & 2.22 & & 0.37 & & $1.17-3.00$ & $1.00-3.00$ \\
\hline Standardized ratings & 147 & 0.25 & & 0.91 & & $-1.86-2.15$ & \\
\hline \multicolumn{8}{|l|}{ Academic self-concept } \\
\hline SDQ-I & 141 & 3.13 & & 0.61 & & $1.33-4.00$ & $1.00-4.00$ \\
\hline \multicolumn{8}{|l|}{ Classroom participation } \\
\hline Cooperative & 147 & 2.73 & & 0.37 & & $1.50-3.00$ & $1.00-3.00$ \\
\hline Independent & 147 & 2.45 & & 0.51 & & $1.00-3.00$ & $1.00-3.00$ \\
\hline \multicolumn{8}{|l|}{ First grade achievement } \\
\hline Reading chart 1 & 141 & 39.72 & 39.84 & 17.52 & 18.47 & $5.00-92.00^{a}$ & $A-E^{b}$ \\
\hline Reading chart 2 & 141 & 24.54 & 25.24 & 16.10 & 16.72 & $0.00-86.00^{a}$ & $A-E^{b}$ \\
\hline Reading chart 3 & 141 & 14.65 & 15.61 & 10.51 & 12.24 & $0.00-44.00^{a}$ & $A-E^{b}$ \\
\hline Spelling & 141 & 30.87 & 29.93 & 6.63 & 8.21 & $0.00-39.00$ & $0.00-39.00$ \\
\hline Mathematics & 141 & 22.23 & 22.93 & 9.43 & 9.42 & $4.00-39.00$ & $0.00-40.00$ \\
\hline
\end{tabular}

Note. $M_{\text {Sibo }}=$ Mean in the SiBO sample, $S D_{\text {Sibo }}=$ Standard deviation in the SiBO sample.

a The scores on the reading charts represent the amount of words read correctly within the specific time set.

b Skill zone $\mathrm{A}=$ percentiles $76-100$, skill zone $\mathrm{B}=$ percentiles $51-75$, skill zone $\mathrm{C}=$ percentiles $26-50$, skill zone $\mathrm{D}=$ percentiles $11-25$, skill zone $\mathrm{E}=$ percentiles $1-10$. 
Table 2

Bivariate relations among the variables.

\begin{tabular}{|c|c|c|c|c|c|c|c|c|}
\hline Variable & 1. & 2. & 3. & 4. & 5. & 6. & 7. & 8. \\
\hline 1. Cognitive ability & - & $.26^{* *}$ & -.08 & $.47^{* * *}$ & .09 & .06 & $.26^{* *}$ & $.37^{* * *}$ \\
\hline 2. SES & & - & -.17 & $.39^{* * *}$ & .14 & -.02 & $.19^{*}$ & $.36^{* * *}$ \\
\hline 3. Gender ${ }^{a}$ & & & - & -.10 & $-.40^{* * *}$ & -.14 & $-.28^{* *}$ & -.04 \\
\hline 4. Achievement (KG) & & & & - & $.20^{*}$ & .09 & $.34^{* * *}$ & $.55^{* * *}$ \\
\hline 5. Peer acceptance & & & & & - & .08 & $.34^{* * *}$ & .16 \\
\hline 6. Ac. Self-concept & & & & & & - & $.23^{* *}$ & .02 \\
\hline 7. Class. participation & & & & & & & - & $.47^{* * *}$ \\
\hline 8. Achievement (1 G) & & & & & & & & - \\
\hline
\end{tabular}

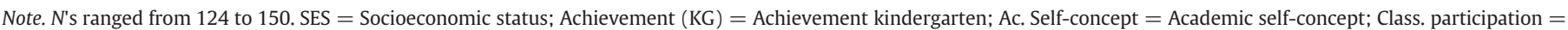
Classroom participation; Achievement $(1 \mathrm{G})=$ Achievement 1st grade.

${ }^{*} p<.05$. ${ }^{* *} p<.01 .{ }^{* * *} p<.001$.

a Girls $=0$, boys $=1$.

were not significant (i.e., from peer acceptance in kindergarten to academic self-concept, and from academic self-concept to achievement at the end of first grade). These paths were removed to enhance parsimony. The resulting model had a good fit to the data: $\chi^{2}(3)=1.61$, $p>.05$, RMSEA $=0.00$, SRMR $=0.03$, CFI $=1.00, R^{2}=0.21$.

In a second step, achievement in kindergarten was entered in the model. An extra path from achievement at the start of kindergarten to academic self-concept a few months later was added. The fit indices indicated some room for improvement: $\chi^{2}(5)=53.06, p=.00$, RMSEA $=0.25$, SRMR $=0.13, \mathrm{CFI}=0.51, R^{2}=0.21$. Consequently, following the procedures outlined above, a specification search was conducted. Two paths were added, that is, a direct path from achievement in kindergarten to achievement at the end of first grade, and a direct path from achievement in kindergarten to classroom participation in first grade. This model proved to have a good fit: $\chi^{2}(3)=1.36, p>.05$, RMSEA $=0.00$, SRMR $=0.02$, CFI $=1.00, R^{2}=$ .39. However, one path in the model was not significant (i.e., from achievement in kindergarten to academic self-concept). This path was removed, resulting in a model with excellent fit indices: $\chi^{2}(4)=1.98$, $p>.05$, RMSEA $=0.00$, SRMR $=0.03$, CFI $=1.00, R^{2}=.39$.

In a third step, the three entry factors (i.e., cognitive ability, gender, and SES) and their hypothesized links with peer acceptance and achievement at the start of kindergarten were added simultaneously. Again, the fit indices indicated some room for improvement: $\chi^{2}(13)=$ $18.24, p>.05$, RMSEA $=0.05$, SRMR $=0.05, \mathrm{CFI}=0.97, R^{2}=.39$; and a specification search was conducted. Two paths were added (i.e., from SES to achievement in first grade and from gender to participation in first grade) and the non-significant paths (i.e., from gender to achievement in kindergarten, and from SES and cognitive ability to peer acceptance in kindergarten) were removed one by one to enhance parsimony, resulting in a good fit: $\chi^{2}(14)=10.09, p>.05$, RMSEA $=0.00$, SRMR $=0.04, \mathrm{CFI}=1.00, R^{2}=.41$. The final model is displayed in Fig. 2.
Results are summarized in Table 3. The direct, indirect, and total effects of each variable on first grade achievement are described. The relative importance of the direct effects and indirect effects (i.e., effects through associations with other, intervening variables) is described in terms of percentages of the total effect.

Results indicate that classroom participation in first grade had a significant positive effect on achievement at the end of first grade. Furthermore, kindergarten factors contributed significantly to the prediction of achievement at the end of first grade. Achievement at the beginning of kindergarten had the largest predictive value of all variables included in the model and had mainly a direct effect on achievement at the end of first grade. A smaller, but significant indirect link from kindergarten achievement to first grade achievement was established through classroom participation in first grade $(z=3.01 ; p<.01)$. Furthermore, peer acceptance and academic self-concept both had a small, but significant positive indirect effect on achievement. As displayed in Fig. 2, both academic self-concept and peer acceptance were associated with achievement through classroom participation (academic self-concept $=z=2.17 ; p<.05$; peer acceptance $=z=2.28 ; p<.05$ ).

Among the entry factors, SES added significantly to the prediction of achievement at the end of first grade. The total effect of SES was generated by a direct and an indirect association, which followed two different, both significant paths: One through prior achievement in kindergarten $(z=3.40 ; p<.001)$, the other through prior achievement and classroom participation $(z=2.54 ; p<.05)$. The effect of cognitive ability on achievement at the end of first grade was entirely indirect and followed the same two significant indirect paths as found for SES; one by way of prior achievement in kindergarten $(z=$ 3.52; $p<.001)$, the other by way of classroom participation $(z=$ $2.81 ; p<.01)$. The final entry factor, gender, had a small total effect on achievement at the end of first grade, favoring girls. The gender effect on achievement was entirely indirect, involving two different

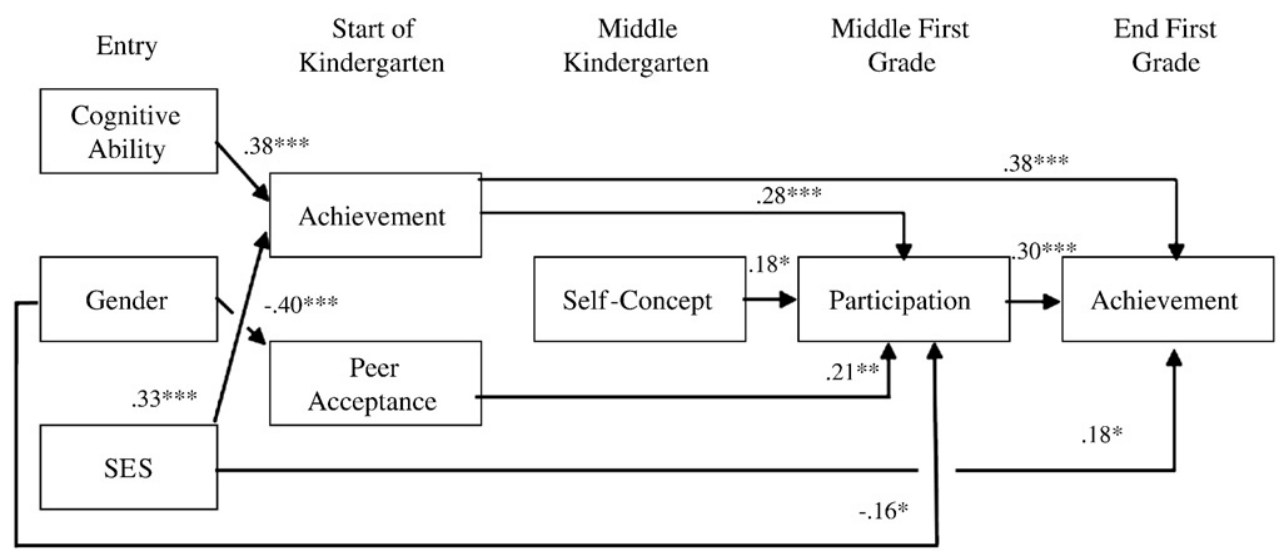

Fig. 2. Standardized path coefficients of the final model, predicting achievement at the end of first grade. SES $=$ Socioeconomic status. ${ }^{*} p<.05 .{ }^{* *} p<.01 .{ }^{* * *} p<.001$. 
Table 3

Total effects of entry factors, kindergarten and first grade factors on achievement at the end of first grade.

\begin{tabular}{|c|c|c|c|c|c|}
\hline Predictors & Direct effect achievement & Percent of total effect & Indirect effect achievement & Percent of total effect & Total effect achievement \\
\hline Cognitive ability & - & 0 & $.18^{* * *}$ & 100 & $.18^{* * *}$ \\
\hline SES & $.18^{*}$ & 55 & $.15^{* * *}$ & 45 & $.33^{* * *}$ \\
\hline Gender & - & 0 & $-.07^{* *}$ & 100 & $-.07^{* *}$ \\
\hline Achievement KG & $.38^{* * *}$ & 82 & $.09^{* *}$ & 18 & $46^{* * *}$ \\
\hline Peer acceptance & - & 0 & $.06^{*}$ & 100 & $.06^{*}$ \\
\hline Ac. Self-concept & - & 0 & $.05^{*}$ & 100 & $.05^{*}$ \\
\hline Classroom particip. & $.30^{* * *}$ & 100 & - & 0 & $.30^{* * *}$ \\
\hline
\end{tabular}

Note. $N=153$. SES = Socioeconomic status; Achievement KG = Achievement in kindergarten, Ac. Self-concept = Academic self-concept; Particip. $=$ Participation.

${ }^{*} p<.05{ }^{* *} p<.01 .{ }^{* * *} p<.001$.

pathways. However, the path through classroom participation, was the only indirect path in the model that was not significant $(z=-1.92 ; p>.05)$. The second path, through peer acceptance and classroom participation was significant $(z=-2.18 ; p<.05)$.

\section{Discussion}

In the current study, we focused on children's transition to first grade, and more specifically on factors that shape first grade achievement. We constructed and tested a comprehensive model, based on the parallel processes mediation model proposed by Buhs (2005). The model of Buhs (2005) proved to be partially valid. First, we found support for the predicted indirect link between peer acceptance at the start of kindergarten and achievement at the end of first grade, through classroom participation. This is in line with former findings in other age groups, where peer status predicted achievement through its effect on classroom engagement (Buhs \& Ladd, 2001; Buhs et al., 2006; Ladd et al., 1999; Wentzel, 2003). Second, we found support for an indirect effect of academic self-concept in kindergarten on achievement at the end of first grade, through classroom participation, thereby linking aspects of self, subsequent action patterns, and achievement outcomes as predicted by Buhs's model. Additionally, in the final model, classroom participation partially mediated the effect of prior achievement in kindergarten on achievement at the end of first grade. Together, these findings underline the importance of the behavioral component of classroom engagement, "i.e., classroom participation". Children's participation in the classroom proves to be a key intervening construct linking both context-related (e.g., peer acceptance) and self-related predictors (e.g., academic self-concept) to later achievement outcomes (e.g., Buhs, 2005; Fredricks et al., 2004; Ladd et al., 1999; Skinner et al., 2008). These findings are in line with former research that depicts the positive short term effects (e.g., grades, achievement test scores) and long term effects (e.g., attendance, graduation) of classroom engagement (e.g., Connell, Spencer, \& Aber, 1994; Fredricks et al., 2004; Sinclair, Christenson, Lehr, \& Anderson, 2003) and extend them to the kindergarten-first grade transition period.

However, not all pathways included in the parallel processes mediation model were found to be significant. In particular, no direct links were found of academic self-concept with prior peer acceptance and later academic achievement. Academic self-concept was only related directly with classroom participation in first grade. Several explanations for this lack of associations can be provided. First, the lack of a link between peer acceptance and academic self-concept may be due to the specific domain of the self-concept (i.e., academic) that was probed. Although links of peer acceptance with academic selfconcept have been found in former research, stronger correlations have been found with the social dimension of the self-concept (e.g., Tarquin \& Cook-Cottone, 2008). Second, because former research was mainly conducted among older children, some developmental considerations might have to be taken into account. From a developmental perspective, young children's self-perceptions are known to be more inflated, less differentiated, and less connected with external indicators (e.g., achievement) than older children's selfperceptions (Guay et al., 2003; Harter, 2006; Marsh, 1990; Marsh et al., 1998). These developmental differences may also explain why the connections with academic self-concept were less prominent than expected based on older samples (Marsh, 1990; Marsh et al., 1998).

Another main research question pertained to the direction of effects between academic self-concept and academic achievement among young children. Therefore, children's prior achievement was explicitly added into the model. This way, both the effects of prior achievement on academic self-concept (i.e., skill development process) and of academic self-concept on later achievement (i.e., self-enhancement process) could be modeled. As could be expected, children's prior achievement level at the beginning of kindergarten had the largest effect on achievement at the end of first grade, which is in line with results from former studies (e.g., Downer \& Pianta, 2006; La Paro \& Pianta, 2000). This finding underscores the cumulative nature of achievement, even in young children, and before the transition from informal to formal schooling. However, no link was found between achievement at the start of kindergarten and academic self-concept a few months later (i.e., the skill development process). The current results were more in favor of a self-enhancement model, in which academic self-concept in kindergarten predicts later achievement in first grade, more specifically through its effect on children's classroom engagement. In former studies among slightly older children (second, third, and fourth grade, Guay et al., 2003), evidence for both directions of effect has been found, although self-enhancement processes appeared to be stronger than skill-development processes in all age cohorts. A possible explanation for not finding an effect of prior achievement on the academic selfconcept in our study may be that the social environment of kindergartners is less focused on children's achievement, compared to when formal education starts in first grade. Feedback based on achievement levels may be provided less often to kindergarten children and consequently, the impact on academic self-concept may be less strong. This weaker link, combined with the relatively small sample, may explain why skilldevelopment processes remained undetected.

Finally, to account for child and environmental attributes that operate prior to children's school entrance, three entry factors (i.e., cognitive ability, SES, and gender) were added to the main model. Two general conclusions can be drawn concerning these entry factors. First, entry factors were found to add to the prediction of academic achievement in the first grade, mainly through their connections with cognitive or psychosocial factors in kindergarten. Interestingly, the effects of cognitive ability and SES were by way of cognitive factors (i.e., achievement) in kindergarten, whereas the effect of gender was by way of its connection with psychosocial factors (i.e., peer acceptance). Second, entry factors also added directly to first grade achievement. Specifically, a direct effect was found between SES and achievement at the end of first grade, even after taking into account prior achievement. In other words, SES-related differences in academic achievement at the end of first grade were partially but not fully explained by prior achievement differences. This implies that a SES-achievement gap already existed at the start of kindergarten, but further widens after the transition to first grade. Other variables (related to differences in SES) may play an 
(increasing) intervening role, such as parental involvement with schoolwork at home and in school (Green, Walker, Hoover-Dempsey, \& Sandler, 2007) and teacher, parents, and peer support (Malecki \& Demaray, 2006).

In conclusion, this study provides a peer-oriented model explaining the effect of peer status, alongside of other relevant factors, such as entry factors and kindergarten achievement, on adjustment in the transition between kindergarten and first grade. We acquired a more precise view of how these variables relate with each other over time and affect achievement at the end of first grade. The final model accounted for a substantial part of the variability in academic achievement in first grade, stressing its significance.

\section{Limitations and suggestions for future research}

Some limitations of this study are worthy of discussion. First, not all variables included in the parallel processes mediation model of Buhs were measured at every time point, thereby excluding the possibility to test competing models with alternative ordering of variables. Second, additional components of context, self, and action may be considered to enrich the model. For example, earlier research has revealed that student-teacher relationships have an important effect on children's academic self-concept (see Leflot, Onghena, \& Colpin, 2010), especially for young children (Wentzel, 2004). Therefore, student-teacher relationships are another interesting indicator of the context-component to include in further studies. Regarding aspects of self, as mentioned above, social self-concept may be added to the model. Furthermore, behavioral classroom engagement is only one out of three components constituting classroom engagement (Fredricks et al., 2004). Although the behavioral component of classroom engagement has the strongest relations with academic achievement (Ladd \& Dinella, 2009), including the other components (i.e., emotional engagement and cognitive engagement) might create an even stronger effect. Third, a large proportion of the total effects of prior kindergarten achievement and SES on first grade achievement was direct. These high percentages raise the question if other variables, not included in this study, might explain these relations. In sum, the integration of other possible components in one comprehensive model may contribute to an optimization of universal screening methods and to more justified choices for early preventive actions enhancing children's school success (cf. Coie et al., 1993).

Fourth, this study was conducted with a fairly small group of Belgian children, most of whom had parents with a high educational degree. Although no significant differences were found in the achievement levels of the children included in our study and the large scaled SiBO study, replication in a larger, more heterogeneous, preferably cross-national, sample remains necessary. In Belgium, attendance rates in nursery education are fairly high compared to other countries (OECD Family Database, 2010). As stated in previous research (e.g., Ladd, Buhs, \& Seid, 2000), the amount of prior school experience might facilitate children's adaptation to formal schooling. Consequently, results may differ in countries with lower attendance rates in nursery education and/or kindergarten. Fifth, although our hypothesized model fitted the data, a specification search was conducted, in search of a better model. According to MacCallum (1986), this approach can merely be seen as an exploratory one, rather than confirmatory. The results displayed here should, therefore, be validated in future research.

\section{Applied implications}

The results of this study have several practical implications for teachers, schools, and policy makers. First, they underscore the cumulative nature of achievement, even during the transition of kindergarten to first grade. Consequently, it is important to invest sufficient time and effort in the instructional quality in (pre) kindergarten classrooms (Pianta et al., 2005). However, recent research in kindergarten classrooms across six states in the U.S.A. has pointed out that much work is yet to be done in the areas of instructional support, classroom organization and management (La Paro et al., 2009). Second, peer acceptance and academic selfconcept in kindergarten were indirectly linked with achievement at the end of first grade, suggesting that kindergarten screenings of children-at-risk for academic failure should also include psychosocial markers of adjustment. Identifying these risk factors in an early stage, before the onset of formal schooling, provides the opportunity to intervene in a timely fashion (Downer \& Pianta, 2006; Ladd et al., 1999). Several intervention programs or methods that have been developed to enhance children's peer acceptance (Harrist \& Bradley, 2003) or children's academic self-concept (e.g., Craven, Marsh, \& Debus, 1991), can be considered for this.

However, classroom participation in first grade was found to be the most important variable included in this study. Not only does classroom participation have a strong link with academic achievement, it also functions as a key intervening variable, connecting various cognitive and psychosocial kindergarten factors with achievement at the end of first grade. Moreover, former research has revealed that classroom participation is only moderately stable across elementary school years (Ladd \& Dinella, 2009). These findings stress the importance and feasibility of enhancing classroom participation throughout elementary school. Consequently, schools should invest in practices that are designed to promote classroom participation (e.g., the Good Behavior Game, Leflot, van Lier, Onghena, \& Colpin, 2010).

\section{References}

Alexander, K. L., Entwisle, D. R., Blyth, D. A., \& McAdoo, H. P. (1988). Achievement in the first 2 years of school: Patterns and processes. Monographs of the Society for Research in Child Development, 53 (2, Serial No. 218).

Algemene Directie Statistiek en Economische Informatie (2004). Population and households. Household and family nuclei. Brussel: Algemene Directie Statistiek en Economische Informatie.

Asher, S. R., Singleton, L. C., Tinsley, B. R., \& Hymel, S. (1979). A reliable sociometric measure for preschool children. Developmental Psychology, 15, 443-444.

Birch, S. H., \& Ladd, G. W. (1997). The teacher-child relationship and children's early school adjustment. Journal of School Psychology, 35, 61-79.

Boivin, M., \& Hymel, S. (1997). Peer experiences and self-perception: A sequential model. Developmental Psychology, 33, 135-145.

Buhs, E. S. (2005). Peer rejection, negative peer treatment, and school adjustment: Selfconcept and classroom engagement as mediating processes. Journal of School Psychology, 43, 407-424.

Buhs, E. S., \& Ladd, G. W. (2001). Peer rejection as an antecedent of young children's school adjustment: An examination of mediating processes. Developmental Psychology, 37, 550-560.

Buhs, E. S., Ladd, G. W., \& Herald, S. L. (2006). Peer exclusion and victimization: Processes that mediate the relation between peer group rejection and children's classroom engagement and achievement? Journal of Educational Psychology, 98, $1-13$.

Bukowski, W. M., \& Hoza, B. (1989). Popularity and friendship: Issues in theory, measurement and outcome. In T. J. Berndt \& G.W. Ladd (Eds.), Peer relationships in child development (pp. 13-45). New York, NY: Wiley.

Byrne, B. M. (1984). The general/academic self-concept nomological network: A review of construct validity research. Review of Educational Research, 54, 427-456.

Cohen, J. (1988). Statistical power analysis for the behavioral sciences (revised edition). Hillsdale, NJ: Erlbaum.

Coie, J. D. (1990). Towards a theory of peer rejection. In S. R. Asher \& J.D. Coie (Eds.), Peer rejection in childhood (pp. 365-401). New York, NY: Cambridge University Press.

Coie, J. D., Watt, N. F., West, S. G., Hawkins, J. D., Asarnow, J. R., Markman, H. J., et al. (1993). The science of prevention. A conceptual framework and some directions for a national research program. The American Psychologist, 48, 1013-1022.

Connell, J. P. (1990). Context, self, and action: A motivational analysis of self-system processes across the life span. In D. Cicchetti \& M. Beeghly (Eds.), The self in transition: Infancy to childhood (pp. 61-97). Chicago, IL: University of Chicago Press.

Connell, J. P., Spencer, M. B., \& Aber, J. L. (1994). Educational risk and resilience in African-American youth: Context, self, action and outcomes in school. Child Development, 65, 493-506.

Connell, J. P., \& Wellborn, J. G. (1991). Competence, autonomy, and relatedness: A motivational analysis of self-system processes. In M. R. Gunnar \& L.A. Sroufe (Eds.), Self-processes in development: Minnesota symposium on child psychology, Vol. 23. (pp. 43-77)Hillsdale, NJ: Erlbaum. 
Craven, R. G., Marsh, H. W., \& Debus, R. L. (1991). Effects of internally focused feedback and attributional feedback on enhancement of academic self-concept. Journal of Educational Psychology, 83, 17-27.

Downer, J. T., \& Pianta, R. C. (2006). Academic and cognitive functioning in first grade: Associations with earlier home and child care predictors and with concurrent home and classroom experiences. School Psychology Review, 35, 11-30.

Dudal, P. (1993). Arithmetic comprehension. Torhout, Belgium: PMS2.

Dudal, P. (2006). Arithmetic comprehension. Two standardized arithmetic tests for the start and the end of first grade. Brussel: VCLB-Service.

Entwisle, D. R., \& Alexander, K. L. (1998). Facilitating the transition to first grade: The nature of transition and research on factors affecting it. The Elementary School Journal, 98, 351-364.

Evers, A., van Vliet-Mulder, J. C., \& Groot, C. J. (2000). Documentatie van tests en testresearch in Nederland [Documentation of tests and test research in the Netherlands]. Assen: Van Gorcum.

Evers, A., van Vliet-Mulder, J. C., Resing, W. C. M., Starren, J. C. M. G., van Alphen de Veer, R. J., \& van Boxtel, H. (2002). COTAN test book for the education system. Boom: NDC.

Finn, J. D. (1993). School engagement and students at risk. ERIC Document Reproduction Service No. ED 362 322. Washington, DC: U.S. Department of Education, National Center for Educational Statistics.

Flook, L., Repetti, R. L., \& Ullman, J. B. (2005). Classroom social experiences as predictors of academic performance. Developmental Psychology, 41, 319-327.

Fredricks, J. A., Blumenfeld, P. C., \& Paris, A. H. (2004). School engagement: Potential of the concept, state of the evidence. Review of Educational Research, 74, 59-109.

Green, C. L., Walker, J. M. T., Hoover-Dempsey, K. V., \& Sandler, H. M. (2007). Parent's motivations for involvement in children's education: An empirical test of a theoretical model of parental involvement. Journal of Educational Psychology, 99, $532-544$.

Guay, F., Marsh, H. W., \& Boivin, M. (2003). Academic self-concept and academic achievement: Developmental perspectives on their causal ordering. Journal of Educational Psychology, 95, 124-136.

Harrist, A. W., \& Bradley, K. D. (2003). "You can't say you can't play": Intervening the process of social exclusion in the kindergarten classroom. Early Childhood Research Quarterly, 18, 185-205.

Harter, S. (1998). The development of self-representations. In W. Damon \& R. M. Lerner (Editors-in-Chief) \& N. Eisenberg (vol. Ed.), Handbook of child psychology: vol. 3 Social, emotional, and personality development (5th ed., pp. 553-617). New York, NY: Wiley.

Harter, S. (2006). The self. In W. Damon \& R. M. Lerner (Editors-in-Chief) \& N. Eisenberg (vol. Ed.), Handbook of child psychology: vol. 3 Social, emotional, and personality development (6th ed., pp. 505-570). New York, NY: Wiley.

Hoglund, W. L. G. (2007). School functioning in early adolescence: Gender-linked responses to peer victimization. Journal of Educational Psychology, 99, 683-699.

Jabionsky, T. (2009). Cooperative learning as an innovative trend in education. New Educational Review, 19, 17-28.

Juvonen, J., Nishina, A., \& Graham, S. (2000). Peer harassment, psychological adjustment, and school functioning in early adolescence. Journal of Educational Psychology, 92, 349-359.

Kline, R. B. (2005). Principles and practice of structural equation modeling (2nd ed.). New York, NY: Guilford.

La Paro, K. M., Hamre, B. K., Locasale-Crouch, J., Pianta, R. C., Bryant, D., Early, D., et al. (2009). Quality in kindergarten classrooms: Observational evidence for the need to increase children's learning opportunities in early education classrooms. Early Education and Development, 20, 657-692.

La Paro, K. M., \& Pianta, R. C. (2000). Predicting children's competence in the early school years: A meta-analytic review. Review of Educational Research, 70, $443-484$.

La Paro, K. M., Pianta, R., \& Cox, M. (2000). Kindergarten teachers' reported use of kindergarten to first grade transition practices. The Elementary School Journal, 101, 63-78.

La Paro, K. M., Rimm-Kaufman, S. E., \& Pianta, R. C. (2006). Kindergarten to first grade: Classroom characteristics and the stability and change of children's classroom experiences. Journal of Research in Childhood Education, 21, 189-202.

Ladd, G. W. (1992). The Teacher Rating Scale of School Adjustment. Chicago, IL: University of Illinois.

Ladd, G. W., Birch, S. H., \& Buhs, E. S. (1999). Children's social and scholastic lives in kindergarten: Related spheres of influence? Child Development, 70, 1373-1400.

Ladd, G. W., Buhs, E. S., \& Seid, M. (2000). Children's initial sentiments about kindergarten: Is school liking an antecedent of early classroom participation and achievement? Merrill-Palmer Quarterly, 46, 255-279.

Ladd, G. W., \& Coleman, C. C. (1993). Young children's peer relationships: Forms, features and functions. In B. Spodek (Ed.), Handbook of research on the education of young children (pp. 57-76). New York, NY: Macmillan.

Ladd, G. W., \& Dinella, L. M. (2009). Continuity and change in early school engagement: Predictive of children's achievement trajectories from first to eight grade? Journal of Educational Psychology, 101, 190-206.

Ladd, G. W., Herald, S. L., \& Kochel, K. P. (2006). School readiness: Are there social prerequisites? Early Education and Development, 17, 115-150.

Ladd, G. W., Herald-Brown, S. L., \& Reiser, M. (2008). Does chronic classroom peer rejection predict the development of children's classroom participation during the grade school years? Child Development, 79, 1001-1015.

Ladd, G. W., Kochenderfer, B. J., \& Coleman, C. C. (1997). Classroom peer acceptance, friendship, and victimization: Distinct relational systems that contribute uniquely to children's school adjustment? Child Development, 68, 1181-1197.

Leflot, G., van Lier, P. A. C., Onghena, P., \& Colpin, H. (2010). The role of teacher behavior management is the development of externalizing behavior: An intervention study. Journal of Abnormal Child Psychology, 38, 869-882.
Leflot, G., Onghena, P., and Colpin, H. (2010). Teacher-child interactions: Relations with children's self-concept in second grade. Infant and child development. Advance online publication.

Lubbers, M. J., Van der Werf, M. P. C., Snijders, T. A. B., Creemers, B. P. M., \& Kuypers, H. (2006). The impact of peer relations on academic progress in junior high. Journal of School Psychology, 44, 491-512.

Lubinski, D., \& Dawis, R. V. (1992). Aptitudes, skills, and proficiencies. In M. D. Dunette \& L.M. Hough (Eds.), Handbook of industrial and organizational psychology, vol. 3. (pp. 1-59). Palo Alto, CA: Consulting Psychology Press.

MacCallum, R. (1986). Specification searches in covariance structure modeling Quantitative Methods in Psychology, 100, 107-120.

Maes, F., Ghesquière, P., Onghena, P., \& Van Damme, J. (2002). Longitudinal research in elementary schools. From research aims to research design. Leuven, Belgium: Steunpunt Loopbanen doorheen Onderwijs naar Arbeidsmarkt.

Malecki, C. K., \& Demaray, M. K. (2006). Social support as a buffer in the relationship between socioeconomic status and academic performance. School Psychology Quarterly, 21, 375-395.

Marsh, H. W. (1988). Self-Description Questionnaire I: Manual and research monograph. San Antonio, TX: The Psychological Corporation.

Marsh, H. W. (1990). The causal ordering of academic self-concept and academic achievement: A multiwave, longitudinal panel analysis. Journal of Educational Psychology, 82, 646-656.

Marsh, H. W., Byrne, B. M., \& Yeung, A. S. (1999). Causal ordering of academic selfconcept and achievement: Reanalysis of a pioneering study and revised recommendations. Educational Psychologist, 34, 154-157.

Marsh, H. W., Craven, R. G., \& Debus, R. (1991). Self-concept of young children 5 to 8 years of age: Measurement and multidimensional structure. Journal of Educational Psychology, 83, 377-392.

Marsh, H. W., Craven, R. G., \& Debus, R. (1998). Structure, stability, and development of young children's self-concepts: A multicohort-multioccasion study. Child Development, 69, 1030-1053.

Ministry of the Flemish Community, Educational Information and Documentation Division (2005). Education in Flanders. The Flemish educational landscape in a nutshell. Brochure. Brussels: Author.

Moelands, F., Kamphuis, F., \& Rymenans, R. (2003). Drie-Minuten-Toets voor Vlaanderen (DMT-V): Wetenschappelijke verantwoording [Three-Minutes-Test for Flanders (DMTV): Scientific justification]. Arnhem, Netherlands: Citogroep.

Moelands, F., \& Rymenans, R. (2003a). School Vorderingen in Spellingvaardigheid voor Vlaanderen (SVS-V). Handleiding. [School Proceedings in Spelling Skills for Flanders (SVS-V). Manual]. Arnhem, Netherlands: Citogroep.

Moelands, F., \& Rymenans, R. (2003b). Drie-Minuten-Toets voor Vlaanderen. Handleiding [Three-Minutes-Test for Flanders. Manual]. Arnhem, Netherlands: Citogroep.

Muthén, B., \& Asparouhov, T. (2002). Using Mplus Monte Carlo simulations in practice: A note on non-normal missing data in latent variable models. Mplus webnotes: No. 2 Version 2, March 22, 2002.

Muthén, L., \& Muthén, B. (1998-2001). Mplus User's Guide. Los Angeles, CA: Muthén \& Muthén.

Muthén, B., \& Satorra, A. (1995). Complex sample data in structural equation modeling. In P. V. Marsden (Ed.), Social methodology (pp. 267-316). Oxford: Blackwell.

Naglieri, J. A., \& Bornstein, B. T. (2003). Intelligence and achievement: Just how correlated are they? Journal of Psychoeducational Assessement, 21, 244-260.

O'Neil, R., Welsh, M., Parke, R. D., Wang, S., \& Strand, C. (1997). A longitudinal assessment of the academic correlates of early peer acceptance and rejection. Journal of Clinical Child Psychology, 26, 290-303.

OECD Family Database (2010, July 7). PF3.2: Enrolment in childcare and pre-schools Retrieved August 13, 2010, from http://www.oecd.org/dataoecd/46/13/37864698. pdf

Peters, C. L. O., \& Enders, C. (2002). A primer for the estimation of structural equation models in the presence of missing data: Maximum likelihood algorithms. Journal of Targeting, Measurement and Analysis for Marketing, 11, 81-95.

Pianta, R., Howes, C., Burchinal, M., Bryant, D., Clifford, R., Early, D., et al. (2005) Features of pre-kindergarten programs, classrooms, and teachers: Do they predict observed classroom quality and child-teacher interactions? Applied Developmental Science, 9, 144-159.

Raven, J. C. (1956). Coloured Progressive Matrices: Sets A, $A_{B}, B$. Oxford: OPP Ltd.

Raven, J. C., Court, J. H., \& Raven, J. (1977). Coloured Progressive Matrices. Manual for Raven's Progressive Matrices and vocabulary scales, section 2. London: H.K. Lewis.

Rubin, K. H., Bukowski, W. M., \& Laursen, B. (2009). Handbook of peer interactions, relationships, and groups. New York, NY: Guilford.

Rymenans, R. (2000). Leerlingvolgsysteem Taal. OBPWO-project 97.06. Eindrapport [Student follow up system Language. OBPWO-project 97.06. Final report]. Antwerpen, Belgium: Universiteit Antwerpen.

Saris, W. E., \& Stronkhorst, L. H. (1984). Causal modeling in nonexperimental research: An introduction to the LISREL approach. Amsterdam: Sociometric Research Foundation.

Simmons, R. G., \& Blyth, D. A. (1987). Moving into adolescence: The impact of pubertal change and school context. Hawthorne, NY: Aldine de Gruyter.

Sinclair, M. F., Christenson, S. L., Lehr, C. A., \& Anderson, A. R. (2003). Facilitating school engagement: Lessons learned from Check \& Connect longitudinal studies. Californic School Psychologist, 8, 29-41.

Sink, C. A., Edwards, C. N., \& Weir, S. J. (2007). Helping children transition from kindergarten to first grade. Professional School Counseling, 10, 233-238.

Skaalvik, E. M., \& Hagtvet, K. A. (1990). Academic achievement and self-concept: An analysis of causal predominance in a developmental perspective. Journal of Personality and Social Psychology, 58, 292-307. 
Skinner, E., Furrer, C., Marchand, G., \& Kindermann, T. (2008). Engagement and disaffection in the classroom: Part of a larger motivational dynamic? Journal of Educational Psychology, 100, 765-781.

Sobel, M. E. (1982). Asymptotic confidence intervals for indirect effects in structural equation models. In S. Leinhardt (Ed.), Sociological methodology 1982 (pp. 290-312). Washington, DC: American Sociological Association.

Suyapa, E., Silvia, M., \& MacCallum, R. C. (1988). Some factors affecting the success of specification searches in covariance structure modeling. Multivariate Behavioral Research, 23, 297-326.

Tarquin, K., \& Cook-Cottone, C. (2008). Relationships among aspects of student alienation and self-concept. School Psychology Quarterly, 23, 16-25.

Teddlie, C., \& Reynolds, D. (2000). The international handbook of school effectiveness research. London: Falmer.

Van Kuyk, J. J. (1996). Handleiding Taal voor Kleuters [Manual language for kindergartners]. Arnhem: Cito.

Verachtert, P. (2003). Longitudinaal onderzoek in het basisonderwijs: Toetsen schooljaar 2002-2003 (LOA-rapport $\mathrm{nr}$. 14) [Longitudinal research in elementary school: Tests school year 2002-2003 (LOA-rapport no. 14)]. Steunpunt 'Loopbaan doorheen onderwijs naar Arbeidsmarkt', Cel Schoolloopbanen in het Basisonderwijs ( $\mathrm{SiBO}$ ), Belgium.

Verachtert, P. (2008). Kindergarten risk factors for early mathematics difficulties. Evidence from the longitudinal SiBO study. Unpublished doctoral dissertation, Department of Educational Sciences, K.U. Leuven.
Verachtert, P., Ghesquière, P., Hendrikx, K., Maes, F., \& Van Damme, J. (2005). Longitudinaal onderzoek in het basisonderwijs: Toetsen eerste leerjaar (schooljaar 2003-2004) (LOA-rapport nr. 30) [Longitudinal research in elementary school: Tests first grade (school year 2003-2004) (LOA-rapport no. 30)]. Steunpunt 'Loopbaan doorheen onderwijs naar Arbeidsmarkt', Cel Schoolloopbanen in het Basisonderwijs (SiBO), Belgium.

Watkins, M. W., Lei, P. -W., \& Canivez, G. L. (2006). Psychometric intelligence and achievement: A cross-lagged panel analysis. Intelligence, 35, 59-68.

Wentzel, K. R. (2003). Sociometric status and adjustment in middle school: A longitudinal study. Journal of Early Adolescence, 23, 5-28.

Wentzel, K. R. (2004). Understanding classroom competence: The role of socialmotivational and self-processes. In R. Kail (Ed.), Advances in child development and behavior. Vol. 32. (pp. 213-241) St Louis, MO: Academic Press.

Wentzel, K. R., \& Caldwell, K. (1997). Friendships, peer acceptance, and group membership: Relations to academic achievement in middle school. Child Development, 68, 1198-1209.

Worland, J., Weeks, D. G., Janes, C. L., \& Strock, B. D. (1984). Intelligence, classroom behavior, and academic achievement in children at high and low risk for psychopathology: A structural equation analysis. Journal of Abnormal Child Psychology, 12, 437-454.

Yuan, K. -H., \& Bentler, P. M. (2000). Three likelihood-based methods for mean and covariance structure analysis with nonnormal missing data. In M. E. Sobel \& M.P. Becker (Eds.), Sociological methodology (pp. 165-200). Washington, D.C.: ASA. 